\title{
Discussion on "B\&R” Strategy and Acceleration of Regional Economic Development
}

\author{
Xi Wu \\ Tongji Zhejiang College, Jiaxing Zhejiang, 314001, China
}

Keywords: “B\&R” strategy; regional economy; development

\begin{abstract}
Since the "Belt and Road" (hereinafter referred to as "B\&R") strategy was proposed in 2013, it has played a very important role in promoting regional economic development. Starting from the important role of "B\&R" strategy in accelerating regional economic development, this paper discusses the new connotation and new requirement of "B\&R" strategy in the new period, and proposes several countermeasures to give play to the advantages of "B\&R" strategy in regional economic development.
\end{abstract}

\section{Introduction}

"B\&R" strategy has very important significance for promoting regional economic development in China. It cannot just facilitate regional economic development, but also is a major strategy with epoch-making significance which is proposed in "the $13^{\text {th }}$ Five-year Plan" under the new situation of economic globalization. It indicates the direction and way for regional cooperation.

\section{Important Role of “B\&R” Strategy in Accelerating Regional Economic Development}

\subsection{Strategic role}

Regional economy is a production complex which forms under the double function of external conditions and internal factors based on certain region in the economic development process. Regional economy can embody objective laws of economic development in different regions, and the relation between connotation and extension. Many regions in China belong to resource-based areas. In current situation, as "B\&R" strategy is implemented deeply, economic transformation and development mode change should be valued in regional economic development to fundamentally promote regional economic development. As "B\&R" strategy is implemented deeply, it offers strategic guidance for accelerating regional economic development. In regional economic development, it is required to regard " $B \& R$ " strategy as the guidance, pay attention to optimization of current situation and defects, organically combine all advantages brought by implementation of "B\&R" strategy with "B\&R" strategy, and enhance upgrading and transformation. Hence, "B\&R" strategy has a strategic role in accelerating regional economic development.

\subsection{Development role}

To accelerate regional economic development, we should treat the development with sustainable view, combine current situation of regional economy to have a basic understanding of economic development urgency, and pay attention to energy conservation and environmental protection in economic development process. "B\&R" strategy sticks to the principle of joint negotiation, joint construction and sharing, practices the idea of sustainable development and takes the way of sustainable development. So in regional economic development, it is required to combine the role of "B\&R" strategy in infrastructure construction, stock to the basic thought of promoting orderly and free flow of economic factors, and focus on the positioning by combining the accurate positioning in the region. "B\&R" strategy has strong development role in formulating development thought, 
direction and countermeasures. So, "B\&R" strategy has development role in accelerating regional economic development.

\subsection{Openness role}

"B\&R" strategy pays more attention to openness tolerance, innovation and development. In the process of regional economic development, it is required to drive regional economic development with more open and tolerant mentality and innovation and development view. But different regions have diverse strategic appeals and priority directions. To promote regional economic development and prosperity, it is required to pay attention to the connection between development planning and strategic design in regional economic development. In other words, the openness degree of regional economy should be enhanced from the perspective of supply and demand. Under the guidance of "B\&R" strategy, the regional economy should be promoted to develop to more open, tolerant and innovative direction. Thus, "B\&R" strategy has openness role in accelerating regional economic development.

\section{New Connotation and New Requirement of "B\&R" Strategy in New Period}

Since the $19^{\text {th }}$ National Congress of the Communist Party of China, cooperation information of countries along the line has improved greatly, and "B\&R" strategy has been lifted to the height of being written into the party constitution, which will bring more profound influence on the world. The cooperation opportunities will increase continuously. But meanwhile, more risks and challenges will be faced. So ion the new period, both the connotation and requirement of "B\&R" strategy change a lot.

\subsection{New connotation of " $B \& R$ ” strategy in new period}

Firstly, openness is stronger. The idea that openness leads to development has been known. Under the globalization background, domestic and overseas economic conditions change continuously in current new economic era. We should be brave in meeting challenges, intensify innovation ability, and optimize openness pattern. "B\&R" strategy is not just the exclusive product of coastal areas. inland provinces also need to play their own roles in the international stage of "B\&R". Only when they keep stronger openness can "B\&R" strategy be improved better. For example, although Jiangxi is an inland city in China, Ganzhou City pioneered in connection with the economic belt of Silk Road, and started the first vegetable train to central Europe. In the new period, the requirements of "B\&R" strategy are broader and deeper. In the open economic way, it is required to focus on further implementation of openness strategy. Especially in regional economic development, although it is just an element in "B\&R" strategy, it is indispensable.

Secondly, stronger interactivity. As the $19^{\text {th }}$ National Congress of the Communist Party of China was convened smoothly, "B\&R" strategy will play its role with stronger interactivity. In the information age, various information technologies are continuously integrated and develop rapidly. Regional economy also develops and the commutation with each country also becomes more profound. Under traditional human-computer interaction precondition, the interactivity between regions and the country and among countries becomes more perfect. The interactivity of different regions and countries in economic development requires being more frequent and profound. The interactivity in resource, commercial form and economy also will continually improve. Thus, the interactivity should improve continuously in regional cooperation. Meanwhile, it is required to enhance SWTO analysis in the interactivity, pay more attention to equality, mutual benefit and mutual help so as to better promote complementation of fund, resource, talent and technology in the interactivity process. Thus, it is required to promote improvement of the interactivity in "B\&R" strategy implementation process, continuously enrich the connotation of interactivity so as to facilitate the implementation of "B\&R" strategy.

Thirdly, stronger inheritance. The $19^{\text {th }}$ National Congress of the Communist Party of China explicitly proposed "not to forget the original intention and bear the mission in mind". It is not just an 
important theme of political life, but also the fundamental precondition of economic development and the basic concept which must be adhered to. Under the guidance of this precondition and basic concept, we should not forget the original intention of economic development in the process of economic construction and regional economic development - seek benefits for people and serve for people. In the implementation process of " $B \& R$ " strategy, it is required to bear the original intention and the mission in mind, focus on innovation and development, stick to the route and original intention of " $B \& R$ " strategy, inherit in development and develop in heritance so as to promote the significance of “B\&R” strategy.

\subsection{New requirements of " $B \& R$ " strategy in new period}

In the new period, the deep implementation of "B\&R" strategy will encounter more difficulties and threats. To accelerate regional economic development, we must have an explicit cognition of the new requirements of "B\&R" strategy: firstly, continue to enhance strategic connection and development with the countries along the Silk Road, and be devoted to construction of bilateral and multilateral friendly cooperation relations; secondly, continue to drive implementation of the projects involving bilateral and multilateral needs and interests, and attract more countries to participate in the construction of "B\&R" strategy; thirdly, enhance attention to the possible threats and risks, and focus in project feasibility research and risk control; fourthly, enhance positive propaganda of "B\&R" strategy and doubts solution. For regional economic development, it is required to stick to the idea of obeying the general situation, scientifically plan and efficiently implement regional economic development strategy based on integral development and the idea of sustainable development during formulating and developing regional economic development so as to better meet the challenges and cope with the future.

\section{Countermeasures to Accelerate Regional Economic Development under "B\&R" Strategy}

"B\&R" strategy plays an indispensable role in regional economic development because of its influence and driving force. It not just closely connects different economic spaces. Besides, the implementation scope and development chance also continue to expand. Even if threats and obstacles appear continuously, we need to seize the opportunity, meet the challenges, continuously innovate, focus on inheritance and enhance development in regional economic development so as to better adapt to the new economic form.

\subsection{To pay attention to improvement of regional economic development strategy planning and enhance improvement of regional economic facilities}

There must be sound development strategy planning for regional economic development. At present, numerous problems and defects exist in formulation of regional economic development planning. In particular, the large gap exists in eastern and western areas, coastal areas and inland areas. Industrial development imbalance is outstanding. Economic facilities remain to improve. The ignorance of profound understanding of "B\&R" strategy in regional economic development causes "B\&R" strategy only becomes formalistic, which seriously affects regional economic development. To accelerate regional economic development, it is required to pay high attention to the important role of "B\&R" strategy implementation, improve existing regional economic development strategy planning by combining the practice of the region, focus on linked development of eastern and western areas, coastal areas and inland areas, narrow the existing development gap, pay attention to industry transformation and upgrading, and promote industrial gradient development. In order to promote the improvement of economic development integration, economic facilities must be improved continuously. In combination of practical conditions and shortcomings of the region, targeted and prospective improvement should be conducted. It is required to construct thorough traffic strategic transportation system, speed up regional interlinking, overcome the shortcomings of geographic position and economic condition, change the defects into the driving force, and change the advantages to the innovation potential. In particular, the west area should pay attention to the locational 
shortcoming, utilize the good opportunity of "B\&R" strategy implementation, improve transportation facilities, enhance opening to the outside world based on the Silk Road and existing economic construction pattern, focus on construction of logistics chain, Internet of Things and information transmission, create new economic development situation and facilitate promotion of radiating capacity of economic market.

\subsection{To grasp the new opportunity of regional economic development and promote communication of “ $B \& R$ ” strategy spirit}

In regional economic development, we can better facilitate communication of "B\&R" strategy spirit only when we grasp the new development opportunity. Especially under the current new media age, the achievements of "B\&R" strategy implementation must be seized in order to continuously develop and communicate the spirit of "B\&R" strategy. Especially when the vision becomes true, the plentiful and substantial achievements gained in the policy, facility, trade, fund and popular support should be used. Meanwhile, thought change and role playing should be valued in the development process. Based on the current situation, it is required to grasp the new achievements gained in "B\&R" strategy implementation, combine the practice, and enhance innovation and optimization. Moreover, when Silk Road spirit is used as the guidance in reginal economic development can we advance better in the development.

\subsection{To accelerate regional economic development and create a new open pattern}

At present, "B\&R" strategy has gained the support and response of over 140 countries and regions along the line. As current trade scope continuously expands, total export-import volume of the B\&R-related countries was as high as USD 110 million in 2017. Besides, convenience level continues to rise. To facilitate stable regional economic development, we must advance with the times and never be complacent. Especially as the trade scale continues to expand, China's investment in many fields has laid a solid foundation for accelerating regional economic development. It is required to create the new open pattern, enhance the driving force of regional economic development, communicate and enhance with all parties, and enhance summarization and improvement of advanced experience so as to better create a new B\&R pattern with global influence.

\subsection{To enhance construction of demonstration area of regional economic development and give play to the demonstration role}

In regional economic development and construction, demonstration area construction should be valued. Especially in underdeveloped area and inland area, it is required to enhance penetration of core concept of "B\&R" strategy, pay attention to construction and investment, classify different areas, strictly follow the set development route and create a demonstration area based on the local place and the whole country. In the meantime, it is required to strengthen technological transformation results, closely combine market demands, create a demonstration base with local characteristics and advantages, continuously expand and grow in mutual learning.

\section{Summary}

In conclusion, "B\&R" strategy plays an indispensable role in facilitating regional economic development. In the new age, new period and new situation, we should bear the mission and original intention in mind, deeply understand the functions of " $B \& R$ " strategy, combine new connotation and new requirements of "B\&R" strategy, and pay attention to implementation of "B\&R" strategy. In regional economic development, we should improve regional economic development strategy planning, enhance improvement of regional economic facilities, grasp the new opportunity of regional economic development, facilitate communication of "B\&R" strategy spirit, stably drive regional economic development, create a new open pattern, strengthen demonstration area construction, and give play to the demonstration function of demonstration area so as to better achieve the original intention of "B\&R" strategy. 


\section{References}

[1] Zou Yuanting, Research on Harmonious Development of Regional Economy under "B\&R" Strategy View, Science \& Technology Industry Parks, 2017(17): 15.

[2] Huang Xiaonna, Analysis on "B\&R" Strategy and Integrative Development of Regional Economy, Technology and Economic Guide, 2017(25): 194.

[3] Guo Aijun, Tao Yinhai, Mao Jinhuang, Coordinated development: new trend of regional economic development strategy - on "B\&R" construction and coordinated development of regional economy , Journal of Lanzhou University (Social Sciences), 2017, 45(04): 11-18.

[4] Wu Yichun, Innovative Development Problems of Regional Economy under "B\&R” Strategy, Chinese \& Foreign Entrepreneurs, 2017(14): 1-2.

[5] Xing Juanhong, Research on "B\&R" Strategy and Integrative Development Path of Regional Economy, Modern Economic Information, 2017(07): 472. 